\title{
A problemática das aves no Aeroporto Bartolomeu Lisandro: risco aviário
}

Nos últimos anos, o número de acidentes e incidentes envolvendo aves e aeronaves aumentou. Muitos aeródromos são construídos nas proximidades de áreas urbanas ou outras áreas que funcionam como atrativos para aves, e muitas dessas aves, não residentes do local, são atraídas por fatores naturais ou antrópicos, como a busca de uma área para descanso, reprodução, busca de alimentos que geralmente são os próprios resíduos descartados incorretamente pela população que vive ao redor desses aeródromos. O presente trabalho tem o objetivo de avaliar as principais causas de colisões de aves com aeronaves, os impactos que são gerados e as medidas que devem ser tomadas a fim de minimizar o problema, visando o aeroporto Bartolomeu Lisandro, localizado na cidade de Campos do Goytacazes. A pesquisa foi feita em base bibliográfica, com consultas a artigos, livros, documentos disponibilizados na internet, e, também, foram realizadas entrevistas aos funcionários do aeroporto. Os resultados apontaram que os principais fatores de atração são os resíduos descartados pela população no entorno desse aeródromo e o antigo vazadouro a céu aberto, que funcionava a aproximadamente 4 quilômetros de distância, que mesmo depois de seu fechamento pela prefeitura, continuou funcionando como local de despejo de resíduos pela população. É necessário que os aeródromos utilizem técnicas para afastar essas aves utilizando medidas preventivas como técnicas de afugentação, modificação de habitats e exclusão, ou remoção. A prefeitura da cidade deveria realizar um trabalho de educação ambiental com a população que vive ao redor do aeroporto para que ela tomasse conhecimento do problema evitando o descarte de resíduos e além disso, outras organizações externas deveriam participar do gerenciamento do risco aviário, assim haveria controle interno e das áreas ao redor do aeroporto.

Palavras-chave: Risco aviário; Colisão; Aeroportos; Segurança Operacional.

\section{The problem of birds at Bartolomeu Lisandro Airport: avian risk}

In recent years, the number of accidents and incidents involving birds and aircraft has increased. Many aerodromes are built near urban areas or other areas that attract birds, and many of these non-resident birds are attracted to natural or anthropogenic factors, such as searching for a resting area, breeding, searching for foods that are usually the waste themselves that are incorrectly disposed of by the population living around these aerodromes. This paper aims to evaluate the main causes of bird collisions with aircraft, the impacts that are generated and the measures that should be taken in order to minimize the problem, aiming at Bartolomeu Lisandro airport, located in Campos dos Goytacazes.. The research was done on a bibliographic basis, with consultations to articles, books, documents made available on the internet, and interviews were also conducted with airport employees. The results pointed out that the main attraction factors are the waste discarded by the population around this aerodrome and the old open pit that operated approximately 4 kilometers away, which even after its closure by the city, continued to function as a place of waste disposal by the population. Aerodromes must use techniques to ward off such birds, using preventive measures such as scaring, habitat modification and exclusion, or removal. The city hall should carry out environmental education work with the population living around the airport to make them aware of the problem avoiding waste disposal and in addition, other outside organizations should be involved in managing avian risk, so there would be control and areas around the airport.

Keywords: Bird risk; Collision; Airports; Operational Safety.

Topic: Administração Pública Ambiental

Reviewed anonymously in the process of blind peer.
Received: $\mathbf{2 1 / 1 0 / 2 0 1 8}$

Approved: 21/11/2018
Layra de Oliveira Silva (iD

Instituto Federal Fluminense, Brasil

http://lattes.cnpq.br/9842216126903243

http://orcid.org/0000-0002-2244-7618

layraolivers.la@gmail.com

Cícero Ferreira Neto (iD

Instituto Federal Fluminense, Brasil

http://lattes.cnpq.br/8924682662231847

http://orcid.org/0000-0002-3985-1078

cfneto47@gmail.com
Referencing this:

SILVA, L. O.; FERREIRA NETO, C.. A problemática das aves no Aeroporto Bartolomeu Lisandro: risco aviário. Revista IberoAmericana de Ciências Ambientais, v.9, n.8, p.310-318, 2018. DOI: http://doi.org/10.6008/CBPC2179-6858.2018.008.0027 


\section{INTRODUÇÃO}

Aves são animais de grande mobilidade, capacidade de adaptação e são consideradas como as 'donas do céu'. Elas estão em toda parte podem sobreviver em áreas rurais ou urbanas se adaptando facilmente. Desde o primeiro voo do 'mais pesado que o ar', realizado por Alberto Santos Dumont, em 1906, o risco de haver colisões de aeronaves com esses animais já existia, visto que por mais que pareça pacífico a divisão do céu entre aves e aeronaves, a convivência entre os dois é considerado de extremo risco, onde uma única ave ao colidir pode causar danos severos como perda total da aeronave e de seus passageiros.

Colisões com aves são constantemente relatadas, desde o início da história da aviação e o risco de ocorrerem tem aumentado a cada dia com o aumento do número de aeronaves de cruzam os céus. 0 primeiro evento com vítima fatal ocorreu no ano de 1912, quando o piloto norte-americano Calbraith Rogers faleceu após colidir com uma Gaivota, em um voo sobre Long Beach, Califórnia (CLEARY et al., 2005). Os números de acidentes podem ser considerados como incertos, pois muitos acidentes fatais ocorreram e não foram consideradas as possibilidades de terem sido causados por aves.

No Brasil, o risco de colisões entre aves e aeronaves pode ser relacionado ao desequilíbrio ecológico gerado pelo crescimento urbano sem o planejamento devido, que gera consequências para a população e para o Meio Ambiente. O crescimento populacional desordenado, os sistemas de coleta pouco eficientes, as péssimas condições de saneamento básico e a enorme quantidade de lixo gerado a cada dia são as condições vividas pelo Brasil.

A dificuldade de controlar a incidência de aves está no fato de que a maioria delas não são residentes das áreas aeroportuárias, e sim das áreas no entorno, exigindo que a maioria das ações para a minimização dos riscos sejam feitas nas áreas ao redor, principalmente através da educação ambiental da população que vive no entorno. No caso da cidade de Campos dos Goytacazes, é possível destacar o antigo vazadouro a céu aberto situado no Bairro Codin, que até hoje funciona como foco de atração de aves para o aeroporto Bartolomeu Lisandro, agindo em desconformidade com as leis em vigor que não permite a presença desses locais dentro de um certo raio de abrangência.

Esse trabalho tem como objetivo abordar as causas das colisões (acidentes ou incidentes) de aves com aeronaves, os impactos e as medidas que devem ser tomadas a fim de minimizar esse problema, principalmente no aeroporto analisado através de um estudo preliminar, tomando como base o conceito de Risco aviário e as leis em vigor.

\section{REFERENCIAL TEÓRICO}

\section{O que é Risco Aviário?}

O Centro de Investigação e Prevenção de Acidentes Aeronáuticos define Risco Aviário como a presença de ave ou bando de aves no solo ou no espaço aéreo, que pode causar danos à aeronave ou lesões às pessoas durante sua operação (PESSOA NETO et al., 2006). No Brasil, eventos que envolvem aeronaves e 
fauna não são raros. Foram registrados somente no ano de 20166.023 eventos, considerando colisões, quase colisões e avistamento de fauna (CENIPA, 2017).

A simples presença de aves em áreas de tráfego de aeronaves deve ser vista como arriscada, pois devido à alta velocidade e sua consequente energia cinética gerada pelo avião, independentemente do tamanho da ave, sozinha ou em bando, representa um alto risco de acidente. As colisões entre aves e aeronaves podem gerar prejuízos econômicos, operacionais e perda de vidas humanas (ALLAN, 2002; THORPE, 2012).

Grande parte das colisões que envolvem aves e aeronaves ocorrem, principalmente, em aeroportos porque na maioria das vezes estes locais são fontes de alimentos, locais para pouso e nidificação, tanto nas áreas próximas às pistas de pouso, quanto em áreas de vegetação nativa em suas redondezas. Além disso, as próprias rotas aeronáuticas estão situadas nas rotas de voo que são utilizadas todos os dias por muitas aves (MOEED, 1976).

\section{Acidentes e Incidentes}

As colisões de aves com aeronaves podem ocorrer de maneira insignificante ou grave, levando a perda da aeronave, tripulantes e passageiros. A partir desse fato, o CENIPA (Centro de Investigação e Prevenção de Acidentes Aeronáuticos) diferencia acidentes de incidentes, através das seguintes definições: Acidente Aeronáutico: Pode ser definido como toda ocorrência durante o período que uma pessoa entra em uma aeronave com o objetivo de realizar um voo e sofre alguma lesão grave ou morte como resultado de estar na aeronave ou em contato com alguma de suas partes, incluindo aquelas que foram desprendidas. Não são considerados acidentes, as ocorrências de lesões geradas de forma natural ou por terceiros ou causadas a pessoas que estavam em áreas não destinadas a passageiros.

Pode também considerar como acidente, os danos gerados à aeronave que causam interferência no seu funcionamento e nas características de voo, o desaparecimento de uma aeronave ou a inacessibilidade de um local onde a mesma caiu. Reason (2005) diz que acidentes são resultados de combinações, que nem sempre são previsíveis, de fatores humanos e organizacionais dentro de um sistema complexo.

Tem-se também a definição de incidente aeronáutico, que é toda ocorrência durante o período de operação de uma aeronave que não chega a ser caracterizada como acidente e que possa afetar a segurança de passageiros e tripulantes e a segurança da própria operação. Outro problema que preocupa a aviação são os incidentes envolvendo aves e aeronaves, pois oferecem risco potencial à vida das pessoas e geram gastos financeiros devido às perdas de aeronaves. (NOVAES et al., 2010).

\section{Probabilidade}

O estudo parte do princípio de que a probabilidade de ocorrerem acidentes e incidentes está relacionada com o número de pássaros dentro ou nas proximidades dos aeródromos. Sendo assim, essa probabilidade tende a diminuir quando esse número é reduzido. Segundo Oaci (1978, citado por NETZEL et al., 2004), os fatores que mais contribuem para a atração de aves dentro de um aeroporto ou seus arredores 
estão ligados à busca por alimentos, locais para nidificação, abrigo, segurança, à presença de formações aquáticas e áreas para descanso.

A probabilidade de colisão relaciona o fluxo de aeronaves que operam em determinado aeroporto com a quantidade de aves presentes nesses locais de operação, seja no solo ou em voo. A gravidade está relacionada à velocidade da aeronave e da massa da ave. Então, quanto maior a velocidade da aeronave e maior o peso da ave, mais forte será a colisão e mais graves serão as consequências geradas (ANAC, 2011). Segundo Souza (2003) severidade dos danos e lesões causados pela colisão deve considerar fatores como a velocidade da aeronave em uma determinada situação de voo, o peso da ave e o local da colisão.

A probabilidade de uma ave colidir com uma aeronave é dada em função da quantidade de aves presentes nas rotas de voo das aeronaves e do número de vezes que eles se cruzam no espaço aéreo. É importante considerar como um perigo potencial, tanto uma ave pequena sozinha quanto um bando de aves de qualquer tamanho, porque as colisões sempre oferecem perigo às aeronaves (SOUZA, 2001).

\section{Aumento da população de pássaros}

A vegetação tem grande influência na quantidade de pássaros que vivem próximos aos aeródromos. Quando a vegetação é muito alta e descuidada, há uma maior proliferação de insetos que funcionam como fonte alimentação para pássaros, que passam a residir no local construindo seus ninhos, acarretando também, na proliferação de roedores e cobras que também são atrativos para aves noturnas como corujas e gaviões, falcões, entre outras. A vegetação baixa também pode atrair algumas espécies, como por exemplo o quero-quero, que é um pássaro muito comum nos aeródromos brasileiros (BARRETO et al., 2008).

As regiões para a construção de aeródromos devem ser afastadas de centros urbanos, onde há grande geração de resíduos que funcionam como fonte de alimento para várias espécies de aves, contribuindo para o aumento da população dessas aves nas proximidades dos aeródromos. No entanto, é preciso uma mudança na cultura da sociedade para que haja uma utilização correta de hábitos relacionados ao descarte de lixo e restos de alimentos, visto que há um descaso da população com o meio ambiente (NETZEL et al., 2004).

O desenvolvimento urbano e o crescimento populacional nos arredores dos aeroportos, atraem atividades comerciais, muitas do ramo de alimentício, que são fonte de atração das aves. Então, pode-se considerar que o fator atrativo de aves mais preocupante nas imediações dos aeroportos é a oferta de alimentos. Por isso, é necessário que haja um trabalho de mitigação desses fatores atrativos de aves nas áreas do sítio aeroportuário como política de prevenção, pois se eles forem reduzidos, consequentemente, haverá uma redução na quantidade das aves no aeroporto, já que vão à procura de outros locais (FERNANDES, 2017).

As aves procuram áreas próximas aos aeroportos devido a fatores atrativos como abrigo, alimento, água ou área para nidificação (CLEARY et al., 2005). Além da presença da ave na área do aeroporto, em alguns casos, as rotas migratórias ou os hábitos de comportamento das aves as conduzem para trajetórias de voo que cruzam circuitos de aproximação de aeronaves em pouso ou saídas de decolagem (BEZERRA et al., 2011). 
É importante também que os aeródromos sejam construídos o mais distante possível de matadouros, lixões, indústrias ou qualquer empreendimento que atraia grande quantidade de pássaros. Além desses fatores, o clima também é um fator determinante no comportamento das aves que habitam os locais próximos aos aeródromos. A noite, as pistas ficam mais aquecidas e com isso aves podem se deslocar para se aquecerem, colocando em risco as operações noturnas.

\section{Aspectos constitucionais}

Em outubro de 1995, o CONAMA (Conselho Nacional de Meio Ambiente) aprovou a Resolução №4, com a participação do CENIPA. Essa resolução estabelece restrições a instalações de empreendimentos ou qualquer outra atividade que possam atrair aves para os aeródromos, determinando como Área de Segurança Aeroportuária (ASA), todas as áreas abrangidas por um raio determinado a partir do centro do aeródromo. Assim, foi determinado como ASA toda região dentro de um raio de $20 \mathrm{~km}$ a partir do centro geométrico de aeroportos que operam de acordo com as regras de voo por instrumento e, $13 \mathrm{~km}$ para os aeródromos que funcionam apenas em condições visuais (BRASIL, 1995).

A resolução determina que as atividades realizadas dentro dessas áreas devem adequar suas operações a fim de minimizar qualquer efeito que possa atrair aves e consequentemente, riscos de colisão. De acordo com o CENIPA (2014), "a resolução prevê a não instalação de atividades atrativas (lixões, curtumes, abatedouros, beneficiadores e pontos de venda de pescado, mercados livres) no interior da ASA".

Em 2012 foi aprovada a Lei federal número 12.725, de 16 de outubro, e essa lei visa o controle da fauna nas proximidades de aeródromos e ainda, estabelece a ASA com raio de 20 quilômetros em todos os tipos de aeródromos. O CENIPA tem incentivado os pilotos a preencherem uma ficha chamada 'ficha CENIPA 15', para que sejam registradas todas as ocorrências de avistamento de aves, colisões ou quase colisões. Essas informações são de extrema importância pois permitem a formação de um banco de dados consistente que contribui para a geração de novas leis visando a diminuição desses riscos (BRASIL, 2012).

\section{METODOLOGIA}

Essa pesquisa pode ser classificada como aplicada, qualitativa, exploratória e bibliográfica, pois visa gerar conhecimentos que permitem a minimização do número de colisões, tomando como base a interpretação de fenômenos para entender as suas causas e soluções indutivamente, observando o próprio local. Os números servem apenas como uma fonte de interpretação de dados, mas não são a base da pesquisa.

A pesquisa teve base bibliográfica, e por isso as principais fontes de dados foram artigos publicados, livros que abordavam os riscos que a fauna pode gerar em áreas aeroportuárias, leis disponibilizadas na internet e outros documentos que foram de grande significância para o enriquecimento da pesquisa, além de perguntas abertas aos funcionários do aeroporto.

As perguntas foram relacionadas ao número de colisões que já ocorreram durante as operações do aeroporto, ao monitoramento feito no local, às espécies de aves predominantes na região do aeródromo, ao 
antigo vazadouro a céu aberto que funcionava dentro da ASA e à colaboração da população que vive ao redor do aeroporto. Todas as informações foram reunidas e analisadas, comparando-as entre si e analisando as possíveis causas e as possíveis soluções para o risco de fauna no aeroporto. Durante a pesquisa, também foram coletados dados sobre as características do aeroporto para melhor detalhamento e entendimento dos resultados.

\section{Caracterização do Aeroporto Bartolomeu Lisandro}

O Aeroporto Bartolomeu Lisandro está localizado no município de Campos dos Goytacazes, no estado do Rio de Janeiro, às coordenadas geográficas 21ำ2'04"S / 4118'28"W. Foi inaugurado em 19 de outubro de 1952, e em 1987 a Infraero tornou-se a responsável pela administração do aeroporto, com o objetivo de voos regulares e operações offshore. Em 2013 o aeroporto sofreu obras para a revitalização de sua pista de pouso e decolagem, e instalação de torres para a iluminação do pátio, devido ao aumento do fluxo de passageiros, graças às operações offshore que aumentaram desde a descoberta do pré-sal. Neste mesmo ano ocorreu a municipalização do aeroporto, que concedeu a administração deste para a cidade de Campos dos Goytacazes, por um prazo de 35 anos.

\section{RESULTADOS E DISCUSSÃO}

\section{Pássaros residentes nas proximidades do aeroporto}

Por se localizar relativamente afastado do grande centro urbano da cidade, o Aeroporto Bartolomeu Lisandro, possui uma diversidade relativa de aves que permanecem constantemente nas suas proximidades, trazendo consequências e representando uma ameaça constante ao seu funcionamento. Encontra-se sempre uma concentração de Urubus (Coragyps atratus), Quero - quero (Vanellus chilensis) e Corujas Buraqueiras (Athene cunicularia). A figura 1 mostra que os três tipos de aves mais incidentes no aeroporto Bartolomeu Lisandro estão entre as cinco espécies mais envolvidas com colisões no Brasil.

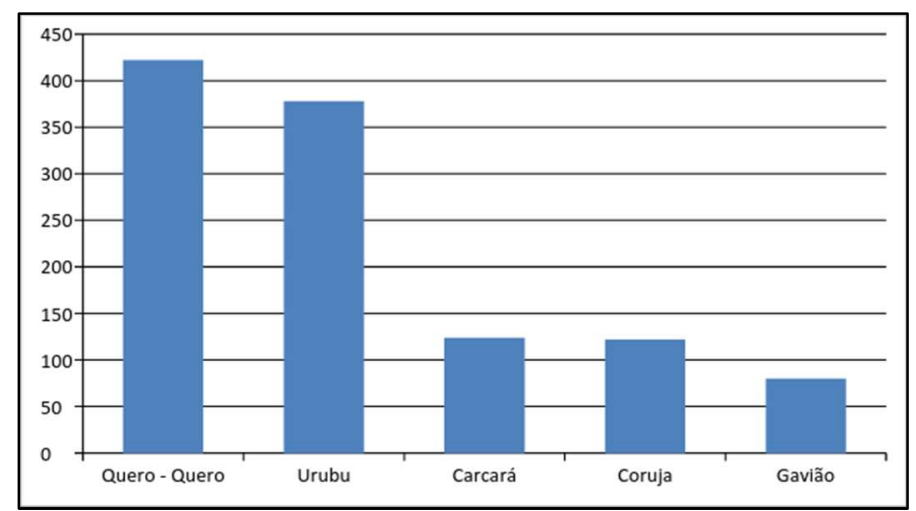

Figura 1: Aves e sua contribuição em colisões no Brasil, entre 2006 e 2010. Fonte: CENIPA (2014).

\section{Como esses pássaros são atraídos?}

Os funcionários do Aeroporto Bartolomeu Lisandro informaram que a maioria dos casos envolvendo aves no aeroporto são avistamentos que ocorrem com uma grande frequência durante o dia. Muitas dessas 
aves não têm a sua espécie identificada, mas os funcionários garantem que a maioria das aves que incidem no local são urubus, e afirmaram ainda que a presença constante dessas aves deve-se ao vazadouro a céu aberto situado a aproximadamente quatro quilômetros de distância do aeroporto, no Bairro Codin em Campos dos Goytacazes, que mesmo após o seu fechamento pela prefeitura por ser um atrativo para aves, continuou sendo um local de despejo de lixo pela população.

Outro problema é a falta de conscientização da população ao redor, que muitas vezes sem o conhecimento adequado das consequências que podem ser geradas, descartam resíduos em locais irregulares nas proximidades do aeródromo. Além disso, por mais que esses resíduos sejam descartados em locais mais distantes ainda assim induz o aumento do risco de colisão, ao atraírem aves para as rotas dos aviões. É possível observar também uma grande quantidade de árvores nos arredores do aeroporto, e essas árvores podem funcionar como fonte de alimento, através da disponibilidade dos frutos, e podem funcionar como abrigo para essas aves que constantemente procuram locais para descanso e nidificação.

\section{Medidas e métodos para afugentação}

O aeroporto é constantemente monitorado pelos funcionários, visando o afastamento dessas aves que são atraídas para o local. Esses monitoramentos são informados para a prefeitura e registrados no site ou na ficha CENIPA 15, especificando se foi uma colisão, uma quase colisão ou um avistamento. O número de colisões informado ao CENIPA é utilizado para auxiliar na geração de leis, que visam minimizar esses problemas. A figura 2 mostra a variação nos números de colisões reportadas na cidade de Campos dos Goytacazes, no período de 2009 a 2014.

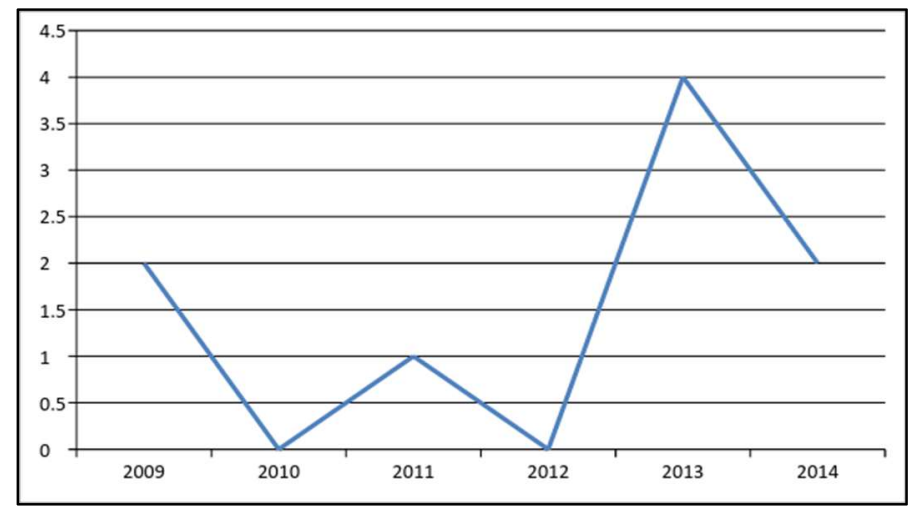

Figura 2: Colisões em Campos dos Goytacazes reportadas por ano (2009 a 2014). Fonte: CENIPA, 2014

O número de colisões reportados na cidade é relativamente pequeno diante dos números reportados em algumas cidades do Brasil. Como exemplo, podemos destacar a cidade de Porto Alegre (RS) que, segundo o CENIPA, no ano de 2014 foram registradas cerca de 121 colisões com aves. Por menor que seja a incidência de aves nestes locais, medidas devem ser tomadas, pois uma simples ave pode causar um estrago em uma aeronave podendo interromper vidas de pessoas que estão a bordos ou até mesmo no solo. A equação mostra como a energia dissipada no impacto se comporta, de acordo com a velocidade da aeronave e a massa da ave que colidiu: $E=\frac{1}{2} m v^{2}$, onde $m$ é a massa da ave e $v$ é a velocidade da aeronave. 
Uma aeronave voando a 130 pés, que equivale a aproximadamente $66,9 \mathrm{~m} / \mathrm{s}$, ao colidir com uma urubu-de-cabeça-preta (Coragyps atratus) de 1,6kg, sofre um impacto equivalente a 3,6 toneladas caindo a 1 metro de altura. Se essa aeronave estivesse sobrevoando a 250 nós e após a decolagem colidisse com o mesmo Urubu, o impacto seria de mais de 13 toneladas.

Diante da complexidade do problema, medidas e técnicas de afugentação podem ser desenvolvidas dentro dos aeródromos ou em suas proximidades, visando afastar e diminuir o número de aves e consequentemente os riscos que elas podem oferecer para a operação. Essas técnicas devem ser usadas de forma integradas para que o resultado seja melhor.

Através da observação do aeroporto, pode-se utilizar as seguintes técnicas para afugentação das aves no local: Modificação do habitat e exclusão: essa técnica visa tornar o ambiente menos atrativo para as aves, reduzindo a disponibilidade de alimento, água, abrigo e consequentemente, o número de aves no aeroporto. É uma técnica barata, mas exige tempo para modificar o habitat corretamente, pois é necessário um estudo tanto das espécies residentes quanto do habitat natural das mesmas; Técnicas de afugentação: essa técnica foi desenvolvida para tornar a área não atrativa para as aves, ou torná-la amedrontadora. Diferentemente das técnicas de modificação e exclusão de habitat que visam reduzir a disponibilidade dos recursos, esta técnica atua afetando os sentidos do animal por meios químicos, auditivos ou visuais.

Além dessas, tem-se a Remoção: que é uma técnica utilizada quando todas as outras falham, pois geralmente é aplicada quando as espécies no entorno do aeroporto estão ameaçadas de extinção, e pode ser seguida de realocação ou abate das aves. Os abates devem ser utilizados em casos extremos pois a administração do aeroporto deverá apresentar estudos consistentes que comprovem a situação de desequilíbrio da fauna, a situação de insegurança para a prática da atividade aérea e a real necessidade deste tipo de intervenção.

\section{CONCLUSÕES}

Acidentes com aves têm se tornado algo constante, principalmente no Brasil, nos últimos anos. Muitos deles são colisões graves que leva a perda de aeronaves gerando grande prejuízo econômico para as empresas, e principalmente, a perda de vidas. Esses fatos demonstram que medidas para reduzir o número e a gravidade desses eventos devem tomadas e praticadas imediatamente, e não ficar apenas no papel.

Analisando todas as causas de atrativos apontadas, pode-se observar que o aeroporto Bartolomeu Lisandro necessita de medidas que sejam aplicadas principalmente nas áreas ao seu entorno, pois a maioria dos focos atrativos de aves são gerados pela própria população. Um trabalho de educação ambiental deve ser feito na população que vive ao redor desse aeródromo, pois muitos descartam resíduos irregularmente em suas proximidades e não tem o conhecimento dos prejuízos e consequências que podem ser geradas.

Esse trabalho de base com a comunidade deve ser feito pela prefeitura que é responsável por fiscalizar todo o entorno do aeroporto Bartolomeu Lisandro. A ausência de uma boa infraestrutura e boas condições de limpeza de locais públicos na cidade também são umas das principais fontes de problemas para a segurança das operações. 
A prefeitura de Campos dos Goytacazes decretou o fechamento do vazadouro a céu aberto que se localizava a poucos quilômetros de distância do Aeroporto Bartolomeu Lisandro e com isso, a incidência de Urubus no aeroporto diminuiu bastante, porém a população continuou descartando lixo no antigo vazadouro e ainda e por isso ainda é possível observar a presença dessas aves constantemente no aeroporto.

É importante que todos os aeródromos pratiquem as medidas de afugentação das aves e com isso gerenciar o risco aviário, mas também é necessário que outras organizações externas participem desse gerenciamento, já que o monitoramento fora do aeródromo é muito importante. Controlar fontes internas de atração se torna relativamente fácil, porém é necessário que haja um controle ainda maior das fontes externas de atração de aves, para que o risco seja minimizado, já que sua eliminação total é impossível.

\section{REFERÊNCIAS}

ALLAN, J. H.. The cost of birds trikes and bird strikes prevention. In: CLARKE, L.. Human conflicts with wildlife: Economic considerations. Fort Collins: US Departamento for Agriculture, 2002. p.147-153.

ANAC. Agência Nacional de Aviação Civil. CSO (Carta de Segurança Operacional). Brasília: ANAC, 2011.

BARRETO, B. M. B.; BARD, E. M.. Perigo aviário. Monografia (Graduação em Pilotagem Profissional) - Faculdade de Ciências Aeronáuticas, Curitiba, 2008.

BEZERRA, G. C. L.; SOUZA, T. A. F.. O papel do biólogo no gerenciamento do perigo aviário em aeroportos. Aviation In Focus, Porto Alegre, v.2, n.1, p.76-89, 2011.

BRASIL. Decreto-Lei n.12725 de 16 de outubro de 2012. Dispõe sobre o controle da fauna nas imediações dos aeródromos. Brasília: DOU, 2012.

BRASIL. Resolução CONAMA n.4 de 9 de outubro de 1995 Brasília: DOU, 1995.

CENIPA. Centro de Investigação e Prevenção de Acidentes Aeronáuticos. Estatísticas: Risco de fauna. Brasília: CENIPA, 2014.

CENIPA. Centro de Investigação e Prevenção de Acidentes Aeronáuticos. Perigo Aviário e Fauna: uma questão permanente. Brasília: CENIPA, 2014.

CENIPA. Centro de Investigação e Prevenção de Acidentes Aeronáuticos. Sistema de Gerenciamento de Risco Aviário (SIGRA): banco de dados. Brasília: CENIPA, 2017.

CLEARY, C. E.; DOLBEER, A. R.. Wildlife hazard management at airports: a manual for airport personnel. 2 ed. Washington: Federal Aviation Administration, 2005.
FERNANDES, F. A. M.. A problemática das aves para a aviação. Monografia (Especialização em Ciências Aeronáuticas) - Universidade do Sul de Santa Catarina, Palhoça, 2017.

MOEED, A.. Birds and their food resources at Christchurch International Airport, New Zealand. New Zeland Journal of Zoology, v.3, p.373-379, 1976.

MORAIS, F. J. A.. Evolução do risco aviário no Brasil entre 2006 e 2010: Estatísticas e probabilidades, v.3, n.2, p.209217, 2012.

NETZEL, C.; ESPINOLA, M.. Estudo preliminar sobre a problemática das aves para a Segurança do aeroporto internacional Tom Jobim e o aterro Sanitário de Gramacho. Monografia (Graduação em Gestão ambiental) - Fundação Getúlio Vargas, Rio de Janeiro, 2004

NOVAES, W. G.; ALVAREZ, M. R. D.. O perigo aviário em aeroportos do nordeste do Brasil: análise das colisões entre aves e aviões entre os anos de 1985 e 2009. Conexão SIPAER, v.1, n.3, 2010

PESSOA NETO, J. A.; TSCHÁ, E. R.; PEDROSA FILHO, M. X. Controle do perigo aviário causado por aves com adoção de medidas mitigadoras. In: CONGRESSO DA SOBER, 44. Anais. Recife: SOBER, 2006.

SOUZA, C. A. F.. Controle do perigo aviário nos aeroportos pela gestão dos fatores de atração de aves. Dissertação (Mestrado) - Universidade de Brasília, Brasília, 2003.

SOUZA, C. A. F.. Procedimentos de Gestão Ambiental em Aeroportos. Monografia (Especialização) - Universidade de Brasília, Brasília, 2001.

THORPE, J.. 100 Years of Fatalities and Destroyed International Bird Strike Conference. Stavanger: 2012.

A CBPC - Companhia Brasileira de Produção Científica (CNPJ: 11.221.422/0001-03) detém os direitos materiais desta publicação. Os direitos referem-se à publicação do trabalho em qualquer parte do mundo, incluindo os direitos às renovações, expansões e disseminações da contribuição, bem como outros direitos subsidiários. Todos os trabalhos publicados eletronicamente poderão posteriormente ser publicados em coletâneas impressas sob coordenação da Sustenere Publishing, da Companhia Brasileira de Produção Científica e seus parceiros autorizados. Os (as) autores (as) preservam os direitos autorais, mas não têm permissão para a publicação da contribuição em outro meio, impresso ou digital, em português ou em tradução. 